Mavi Atlas, 5(2)/2017: 424-437. Araştırma Makalesi | Research Article

Makale Geliş | Received: 09.09.2017

Makale Kabul | Accepted: 27.10.2017

DOI: 10.18795 /gumusmaviatlas.352437

Fatma YILDIRMIŞ

Yrd. Doç. Dr. | Assist. Prof. Dr. Gümüşhane Üniversitesi, Edebiyat Fakültesi, Türk Dili ve Edebiyatı Bölümü, Gümüşhane-Türkiye Gümüşhane University, Faculty of Letter, Dep. of Turkish Language and Literature, Gümüşhane-Turkey

orcid.org/0000-0003-2913-5489

fatma.yildirmis@gumushane.edu.tr

\title{
Trabzon'da Kaybolan Bir Kültür Öğesi: Geleneksel Ahşap Beşik
}

Öz

Beşik, geleneksel yaşam içerisinde Türk kültüründe çok eski zamanlardan beri kullanılmaktadır. Beşik kullanımındaki asıl amaç, bebeğin uyumasını hızlandırmak, onu dış etkilerden korumak ve beşiğin sallanmasını sağlayarak bebeğin rahatlamasına yardımcı olmaktır. Beşik çeşitlerinde teknolojik gelişmelere, gelenek-görenek ve yaşam şartlarına göre farklılıklar görülmektedir. Türk toplumunda eskiden beri yaygın olarak ahşap beşik kullanılmaktadır. Özellikle kırsal kesimlerde bu beşiklerin tercih edilmesinin nedeni, kolay taşınabilir ve pratik olmasıdır. Fakat günümüzde gerek yaşam tarzlarının değişmiş olması gerek modern beşiklerin çıkmasıyla ahşap beşiklerin kullanımı yok denecek kadar azalmıştır. Makalenin konusunu oluşturan ahşap beşikler, Anadolu'nun birçok yerinde olduğu gibi Trabzon'da da yapılarak bir el sanatı hâline gelmiştir. Özellikle de ilin Köprübaşı ilçesi, ahşap el sanatlarının gelişmesine uygun bir coğrafyaya sahiptir. Köprübaşı'nda beşik, kemençe, kaşık, sepet gibi el sanatları yapılmaya devam etmektedir. Makalede beşiğin tanımı ve tarihsel gelişimi hakkında bilgi verildikten sonra yörede beşiğin nasıl yapıldığı incelenmiş ve beşik ile ilgili derlenen sözlü kültür öğelerine yer verilmiştir. Geçmişle günümüz arasında kültürel bağın kurulmasında önemli bir faktör olan el sanatları içinde yer alan beşik, içinde yaşadığı gelenek ve taşıdığı sözlü kültürüyle araştırılmaya ve yaşatılmaya değerdir.

Anahtar Kelimeler: Trabzon, Köprübaşı, Beşik, El Sanatları, Sözlü Kültür Öğeleri.

\section{A Missing Culture Element in Trabzon: Traditional Wooden Cradle}

\begin{abstract}
The cradle has been used in Turkish culture from time immemorial. The main purpose of cradle is accelerating the baby's sleep, protecting him from external injuries, and helping his relief during sleeping by swinging it. The range of the cradles varies according to technological developments, traditions, customs, and life conditions. In Turkish society, wooden cradle has been used commonly for years. Especially, they are preferred in countryside because of being portable and practical. However; the usage of wooden cradles has decreased almost nonexistent due to changing both living conditions and modern cradles. The wooden cradles which are the subject of this study have become handicraft in Trabzon as in lots of places of Anatolia. Especially Köprübaşı distinct has a very suitable geography for developing of handicrafts. In Köprübaşı, handicrafts like cradle, kemancha, spoon, and basket have been still done. In this article, firstly some information is given about the description of cradle, historical developments, then making of cradle in the area is researched and lastly verbal culture elements about the cradle are included. The cradle, which has an important role in connecting both past and present like other handicrafts, is worth to be lived and researched with its traditions and verbal culture.
\end{abstract}

Keywords: Trabzon, Köprübaşı, Cradle, Handicraft, Verbal Culture Elements. 


\section{Beşiğin Tanımı ve Tarihsel Gelişimi}

Beşik, küçük çocukların uyutulmaları esnasında kullanılan hafif, pratik ve basit araçlar olarak geleneksel ve modern biçimleriyle günümüzde de varlığını devam ettirmektedir (Başaran ve Yarmacı 2012: 99). Beşik eski çağlardan beri Türk kültüründe kullanılmaktadır. Türk beşikleri içinde şekil ve süs itibariyle bir sanat ürünü olabilecek derecede güzel olanlar vardır. Bunlar özellikle ceviz, pelesenk, demirhindi, abanoz, servi gibi değerli sert ağaçlardan yapılır, oymalar ve nakışlarla süslenir. Ağaç üzerine kadife kaplanarak gümüş bezemelerle süslenmiş olanları ve som gümüşten yapılanları da vardır. Ağaç üzerine sedef, fildişi ve arusek kakmalı beşikler de yapılmıştır (Türk Ansiklopedisi 1974: 244). Beşik kelimesi, diğer Türk toplumlarında "beşik, besik, bişik, pejik, pezik, pizik, mejik" şeklinde karşılık bulur (Eren 1999: 48). Nitekim beşiklerle ilgili ritüeller bugün çeşitli Türk toplumlarında uygulanmaktadır. Buna Nogay Türklerindeki bir örnek gösterilebilir.

Kuzey Kafkasya'da yaşayan Nogay Türklerinde de bebeğin beşiğe ilk defa konması önemlidir. Buna Nogaylar "besik toy" (beşik dügünü) derler. Bunun için akraba ve komşu kadınlar toplanırlar. Bebeği ilk olarak beşiğe görmüş geçirmiş akıllı bir Nogay kadını koyar. Kadın kundaklanmış bebeği kucağına alıp yanındaki hanımlara "Oñma, solma?" (să $\mathrm{m}$, sol mu?) diye sorar. Yanındakilerin tersini söylemeleri gerekir. Böylelikle çocuğu cinden, şeytandan korumuş olurlar. Daha sonra başka bir kadın beşiğe kamçı ile vurur. Bu da yine aynı inançla yapılır. Kadın çocuğu kundaklayıp beşiğe koyduktan sonra "takpakşı" (atasözü söyleyen), birer beşik yırı söyleyerek çocuğu sallar. Kundaklanan çocuğun baş tarafina "kanş1" (makas), "bastarak" (tarak), "bekizat" (bıçak vb.) konur. Bunların çocuğu kötülüklerden koruyacağına inanılır. Anadolu'da yaşayan Nogay Türklerinde "beşik toy" âdeti unutulmuştur (Ergönenç Akbaba ve Benli 2011: 90-91).

Beşik ile ilgili farklı uygulamalar Osmanlı sultanlarının doğumundan sonraki süreçte de görülmektedir. Sultanların doğumlarından sonra düzenlenen birtakım merasimlerde Valide Sultan ile Sadrazamın tarafından beşik donatılır ve bir alay hazırlanarak gönderilir. Çocuk doğunca padişah validesinin hazırlatmış olduğu beşik, sırmalı puşide denilen örtüsü ve yorganıyla, merasim ve alay ile birlikte eski saraydan yeni saraya getirilir. Beşiğin başucuna Kur'an kesesi, pırlanta elmaslı maşallah veya benzeri şeyler yazılı nesneler mutlaka konur (Akgündüz 2002: 612). Doğumdan beş gün 
sonra ise sadrazamın beşik alayı merasimi düzenlenir. Bu alay Valide Sultan'ınkinden daha şatafatlı ve daha kalabalık olur. Bu merasime devlet erkânının aileleri de davet edilir. Sadrazam, sultan doğar doğmaz bir beşik, bir yorgan ve bir de beşiğe örtü yaptırır, hepsi de inciler, elmaslar, tırtıllar ve zümrütlerle donanır (Eynallı 2014: 9).

Beşik, bebeğin uyuması için bir yatak olmasının dışında bazı Türk topluluklarında mitolojik bir nesne olarak görülmektedir. Örneğin ardıç ağacından yapılan beşiklerin, hem doğurganlığı arttırdığına hem de yeni doğan bebeği kötü ruhlardan, kötü güçlerden ve hastalıklardan koruduğuna inanılır (İsayev 2013: 434). Yine Elazığ'ın Harput ilçesinde bulunan Beşikli Baba Türbesi, mitolojide yer alan koruyucu iyelere bir örnektir. Beşikli Baba Türbesi'nin içinde olan bir beşiğin, kabirdeki kişinin çocuğuna ait olduğuna inanıldığından türbeye bu isim verilmiş ve türbe, çocuğu yaşamayanların veya hiç olmayanların ziyaret ettiği bir mekân hâline gelmiştir. Türbeye gelenler, türbeye beşik veya bebek bırakarak, çocuklarının olacağına veya ölmeyeceğine inanırlar. Yeni doğan ve hasta olan bebekler-çocuklar, türbede birkaç dakika bırakılır. Çocuk ağlarsa yaşayacağına, ağlamazsa öleceğine inanılır (Y1ldız 2013: 885-886).

Türk beşikleri, genel olarak incelendiğinde şekil ve içerik bakımından Türk milletinin tekâmül merhalelerini göstermesi bakımından önemlidir. Beşiğin ağacının yapılış şekli ve içeriği, göçebe toplumun yerleşik hayata geçişine kadar olan sürede farklılık gösterir. Dolayısıyla beşik kullanımı göçebelikten yerleşik hayata geçişin de ifadesidir (Arseven 1950: 214).

Ahşabın ülkemizde hafif, kolay elde edilebilir, taşınabilir, işlenebilir bir yapıda olması kullanım alanlarını genişletmiştir. Gündelik hayatta kullanılan, ahşaptan yapılmış birçok aletin motiflerle süslenmiş ya da sade bir işçilikle oluşturulmuş örnekleri, ahşap işçiliğinin hayatın içinde canlı bir şekilde yaşadığını göstermektedir. Nitekim eski Türklerden kalma eserlerden elde edilen bilgilerde ahşabın gündelik hayattaki yerini gösteren deliller vardır. Makalenin konusu içinde yer alan Trabzon yöresi de ahşap işçiliği bakımından oldukça zengindir. Trabzon'un bitki örtüsü bakımından ormanlarla çevrili olması, yapı malzemesi olarak ahşabın kullanılmasını 
sağlamıştır. Köy ve yayla mimarisinde ahşap, hâlâ vazgeçilmez öğedir. Ayrıca çeşitli ev ve mutfak eşyaları da ahşaptan üretilmektedir. Bunlar arasında şimşir ağacından kaşık, kepçe, ladin ve çamdan çeşitli mutfak eşyaları, süt hayvanları için yem kapları, yayık, yer sofraları, sofra ayakları, ahşap tırmıklar, sepetler, sepet örgüsü iskemleler, beşikler sayılabilir. Makale bu ahşap ürünler arasından beşiği konu edinir. Beşik ilin Köprübaşı ilçesinde yapılmaktadır. İlçenin ormanlarla çevrili olmasının etkisiyle gelir kaynaklarından birisi de ahşap işleri ve ahşaptan yapılan el sanatlarıdır. İlçede beşik, kaşık, kemençe, sepet yapımı hâlen devam etmektedir. Yapılan ürünler, sadece ilçenin değil Trabzon'un da ihtiyacını karşılamakta ve aynı zamanda yerli yabancı turistlere de pazarlanmaktadır.

Genel olarak Doğu Karadeniz beşikleri tamamen boyalıdır. Sarı - kırmızı ve mavi tonlarında olmak üzere iki türlü boyanır. Mavi rengin erkeği, kırmızı rengin kızı simgelediği düşünüldüğünde bu geleneğin beşik renklerine yansıdığı düşünülebilir (Sümerkan 1982: 10). Bir beşikte şu parçalar bulunur: 4 direk, 6 kol, 1 kamara, 4 enlilik, 4 kafes direği, 8 kafes içi, 2 halka, 20 permek, 5 yatacak, 2 kemer, 2 ayak 5 kamara üstlüğü (Öksüz 2005: 31).

Fotoğraf 1: Beşiğin Bölümleri

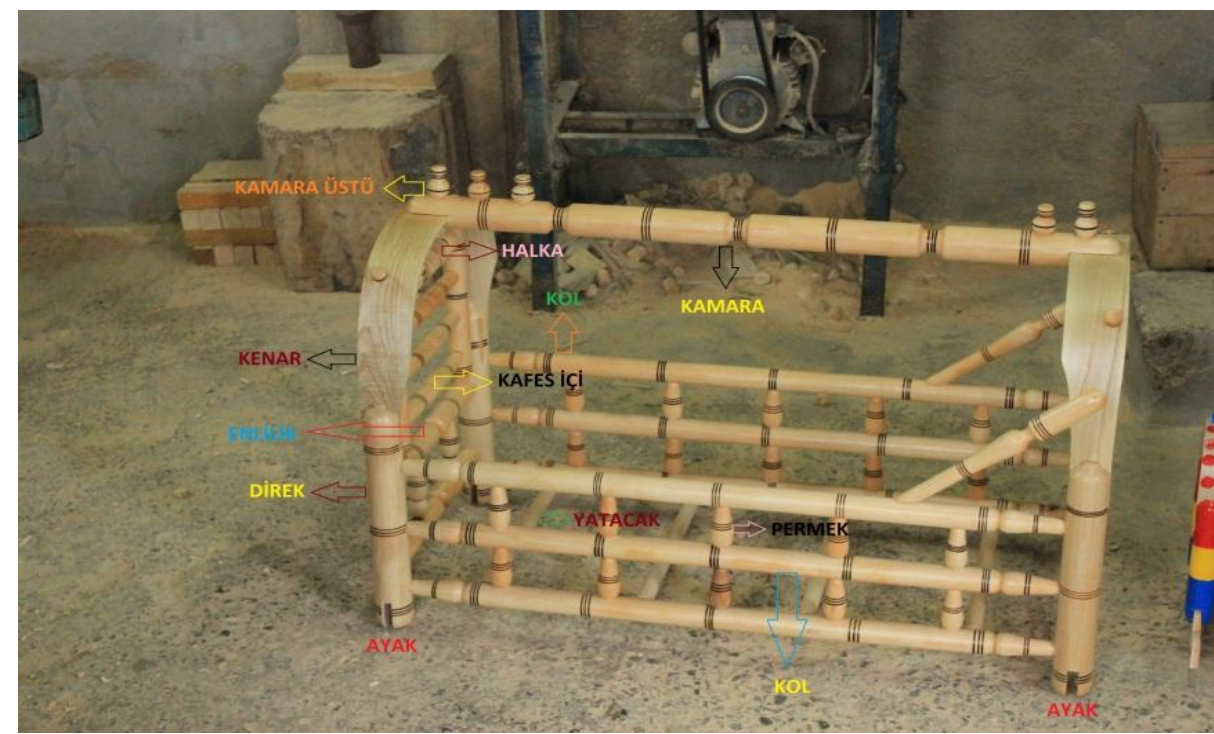


Fatma YILDIRMIŞ, “Trabzon'da Kaybolan Bir Kültür Öğesi: Geleneksel Ahşap Beşik”, Mavi Atlas, 5(2)/2017: 424-437.

\begin{tabular}{|l|l|}
\hline Ürünün Yöresel Adı: & Beşik \\
\hline Ürünün Boyu: & $90 \mathrm{~cm}$ (Büyük) / $35 \mathrm{~cm}$ (Küçük) \\
\hline Ürünün Genişliği: & $45 \mathrm{~cm}$ (Büyük) / $18 \mathrm{~cm}$ (Küçük) \\
\hline Ürünün Yüksekliği: & $70 \mathrm{~cm}$ (Büyük) / $35 \mathrm{~cm}$ (Küçük) \\
\hline Ürünün Malzemesi: & $\begin{array}{l}\text { Kızılağaçtan yapılır. Sadece kuşakları kestaneden } \\
\text { yapılır. }\end{array}$ \\
\hline Ürünün renkleri: & $\begin{array}{l}\text { Kırmızı-Sarı-Mavi gibi karışık renkli ya da } \\
\text { vernikli }\end{array}$ \\
\hline Ürünün Kullanım Amacı: & $\begin{array}{l}\text { Büyükleri kız ve erkek çocukları uyutmak için } \\
\text { kullanılır. Küçükleri genellikle kız çocuklar } \\
\text { tarafindan oyuncak olarak ve evlerde süs olarak } \\
\text { kullanılır. }\end{array}$ \\
\hline $\begin{array}{l}\text { Beşik Yapımında Kullanılan } \\
\text { Aletler: }\end{array}$ & $\begin{array}{l}\text { Düz arda. Oluklu arda, torna, planya, hızar, tepsi } \\
\text { ve matkap }\end{array}$ \\
\hline Yapılışı: & $\begin{array}{l}\text { Hızarda 3X3, 4X4, 2.5X2.5, 5X5 boyutlarında } \\
\text { biçilen ağaçlar 10 gün kadar kurutulur. Tornada } \\
\text { işlendikten sonra boyanır. Boyandıktan sonra } \\
\text { birleştirilir. Genellikle çivisiz yapılır. Kuşak kısmı } \\
\text { tahta veya metal çivi ile tutturulabilir. }\end{array}$ \\
\hline
\end{tabular}

Beşiğin ham maddesi kızılağaç, gürgen ve kiraz ağacıdır. Bu ağaçlar burada yetişiyor. Eskiden el tezgâhlarında şimdi tornalarda yapıyoruz. Oyuncak beşikleri 20 $\mathrm{cm}$, çocukların beşiklerini $90 \mathrm{~cm}$ yapıyoruz (K1). Bir beşiği yaparken ağaçlardan beşe beş, dörde dört kesiyoruz, kurutuyoruz. Montajliyoruz, vernikliyoruz, boyuyoruz. Eskiden sakız boya dediğimiz sonra yün boyalardan ve çam sakızlarından kullanırdık. Renk renk olurdu, şimdi o boyaları bulamazsınız. Yün boyaları toz olurdu. Toz boyalarla çam sakızını karışımından olur. Sakız kaynatıp eritilir, üzerine toz boya dökülür, karıştırılır, beşikler boyanır. Beşiğin kıvrımlı kısımları ağacı kaynatarak 
yumuşatılır, istediğin şekil verilir. Ağaç kuruduğunda öyle kalır (K2). Usta, çam sakızına toz boya karıştırarak beşikleri boyadıklarını ifade ediyor (Öksüz 2005: 32).

Fotoğraf 2: Beşiğin Önden Görünümü

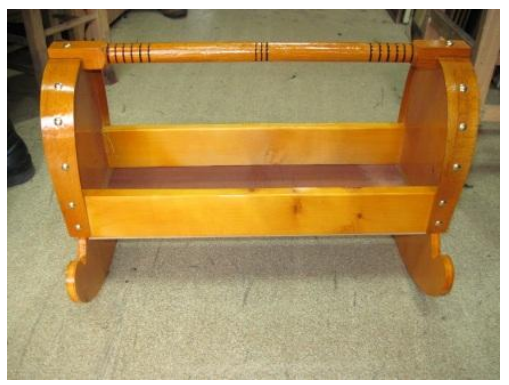

Fotoğraf 3: Beşiğin Yandan Görünümü

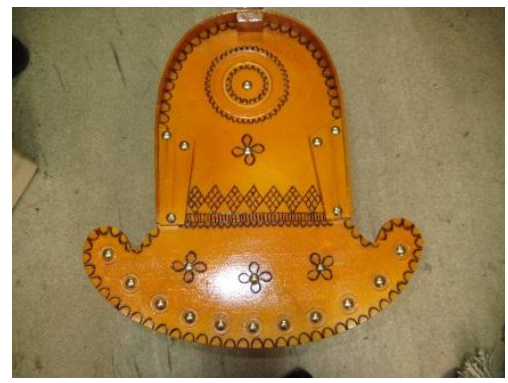

Türk kültürünün önemli bir parçası olan geleneksel ahşap beşikler, modern beşikler karşısında tutunamayıp maddi kültür öğesi olarak müzelerdeki yerini almaya hazırlanmaktadır. Zira bir zamanlar bebeklerin yatağı, uyuma yeri iken şimdi eski işlevini yitirmiştir. Nitekim üreticiler ancak sipariş üzerine beşik yaptıklarını ifade etmektedir. Farklı renk ve şekillerdeki süslü modern beşikler, daha göz alıcı olduğundan insanlar tercihlerini o yönde yapmaktadır. Ayrıca üreticiler, yörede geleneksel boyalı beşiklerin kalmadığını, beşikleri, müşterilerin isteklerine uygun olarak yapıldığını belirtmektedirler.

Fotoğraf 4: Beşik Örnekleri
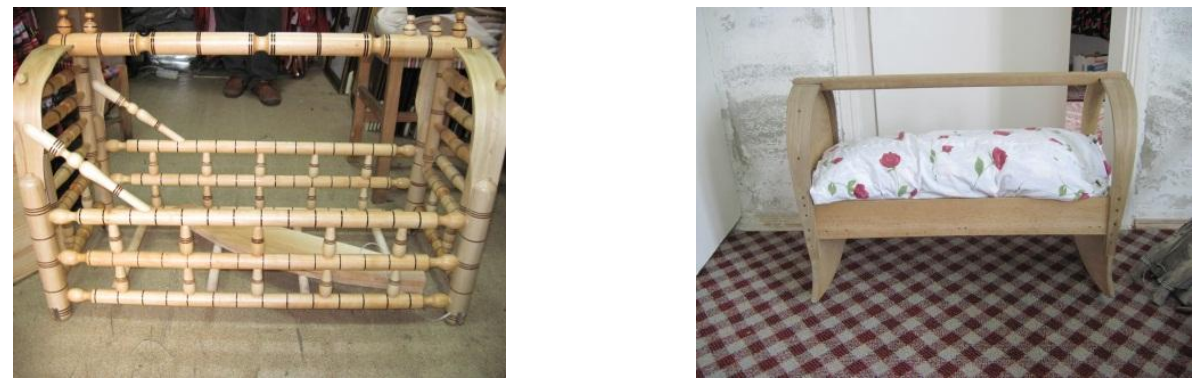

Günümüzde bu sanatı devam ettiren ustalar turistik olarak yapılan süs eşyasına yönelmişlerdir. Küçük ebatlarda yapılan ahşap beşikler hediyelik ya da turistik amaçlı olarak kullanılmaya başlamıştır. Ayrıca bu küçük beşikler çocukların oyuncak 
malzemesi hâline gelmiştir. Bu nedenle üreticiler, bu şekilde yaptığı küçük beşikleri oyuncak mağazalarına pazarlamaktadır.

Fotoğraf 5: Küçük Beşikler

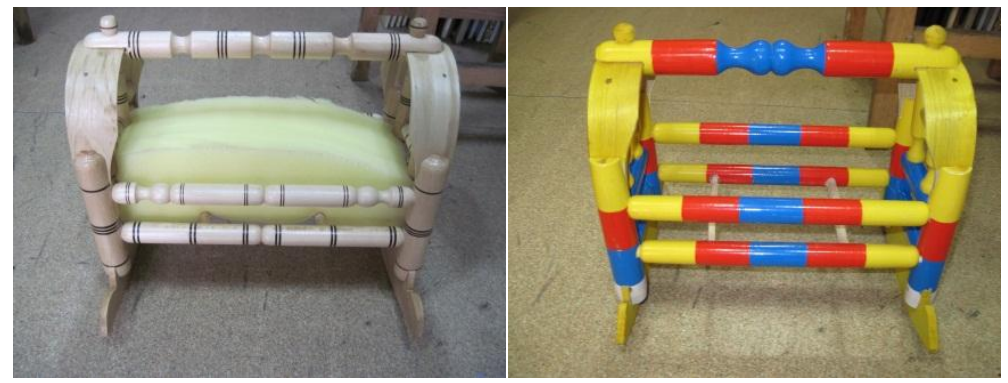

Yörede, maddi kültür olarak ahşap beşik kullanımı azalmasına rağmen sözlü kültür ürünlerinde etkin bir şekilde yaşadığı tespit edilmiştir. Halk yaşayışının ve düşüncesinin dile yansıması sonucu beşik pek çok sözlü kültür ürününde kendine yer bulmuştur. Beşiğin mânilerde, şiirlerde, atasözü ve deyimlerde, bilmecelerde, beddualarda, ağıtlarda yer alması halkın canlı hafızasında yaşadığı anlamına gelmektedir. Tespit edilen bu ürünler aşağıdaki şekliyle örneklendirilebilir.

\section{Beşik ile İlgili Sözlü Kültür Ürünleri}

\section{1. Mâniler}

Ahır altinda hurma

Parla ey gelin parla

Ne küçük kocan vardur

Koy beşuğe da salla (Ciravoğlu 2009: 97).

Akşam oldi güzelim

Işuk yakalım işuk

Etdum sağa beddua

Donatmiyasun beşuk (Çelik 2005: 409).

Aşam oldu gözelim

Yaksene 1şı̆̆ını

Allah alsin elinden

Gınalu beşiğini (Karaca 2000: 371). 
Büyük yaptım evimi

Dakmadım eşiğini

Allah'ım al elinden

Gınalı beşiğini (Çelik 2005: 368).

Çıktım gürgene baktım

Dibi görünmez dibi

Nasıl severdim oni

Beşikteki bebek gibi (Çelik 2005: 346).

\section{2. Şiirler}

\section{Beşik}

Çocuklarımız beşik kertmesi olsun

Sallanıyor beşik

Toprak yoğuran yürekten

Yün eğiren elden hız alarak

Bir acıya bir sevince yaslanarak

Deniz çağrısıyla büyüyor çocuk

Duvarları findık ișleme

Güneş yeşilinde odaları

Çalkalanan gök mavisinde

Küçücük düşlerine sarınarak

Gece ezgisiyle uyuyor çocuk

Hiç yaşanmamış sevi nerde

Sormadım bilmiyorum

$\mathrm{O}$ beni tanımıyor ben onu

Taşıdığımız eski bir beşikte

Uyuyan iki bıçak izi

Törem gelip alnımıza yansıyan

Ac1lar emziren sevda

Seni ben büyütmedim

Hüznü mayalayan bir beşikte

Büyüdün kendiliğginden

Sallanmıyor beşik

Derin bir gök çizgisinde

Gün doğuruyor kendini yeniden

Siliniyor eski bir beşikte

Gizemlenen iki bıçak izi

Çocuklarımız beşik kertmesi olmasın (Mustafa 1982: 3). 


\section{Beşik}

Sallanıyor beşik

Toprak yoğuran yürekten

Yün eğiren elden hız alarak

Bir acıya bir sevince yaslanıp

Kemençe ezgisiyle büyüyor çocuk

Duvarları findık işleme

Güneş yeşilinde odaları

Çalkalanan gök mavisinde

Küçücük düşlerine sarınıp

Deniz sesiyle uyuyor çocuk

Hiç yaşanmamış sevda nerede

Sormadım bilmiyorum

$\mathrm{O}$ beni tanımıyor ben onu

Taşıdığımız eski bir beşikte

Gizlenen iki bıçak izi

Törem gelip alnımıza yansıyan

Acilar emziren sevda

Biz seni büyütmedik

Hüzünler mayalayan bir beşikte

Büyüdün kendiliğinden

Sallanmıyor beşik

Derin bir gök çizgisinde

Gün doğuruyor kendini yeniden

Siliniyor eski beşiklerde

Uyuyan bıçak izleri (Mustafa 2009: 125).

\section{3. A $\breve{g} \mathbf{t} l a r$}

Beşiklerim bebelerim oğul

Nenni nenni gülüme

Çare yoktur ölüme yavrum

Acaba derdi miyum

Acaba eve geldi Mehmet Ali

Mehmet Ali Mehmet Ali

Dünyanın nazli yâri

Ağaçların deste gülü

Sandukların ince bağı Mehmet Ali (Çelik 1994: 20).

Anan buralarda oldu deli oğul

Boş beşiğun besbelli oğul

Baban seni bana beni sana bırakti gitti oğlu

Hepisi de bana el etti oğul (Çelik 1994: 20). 


\section{4. Atasözleri ve Deyimler}

Peşukte giren teneşurde çikar. (Durgun 2005: 533).

\section{5. Beddualar}

Beşik donatmayasın (Duman, 2011: 441).

Aldadın beni yârim

Aldamalan kalasin

Gittuğun yerlerde

Beşuk donatmayasın (Duman 2011: 443).

Beşuğun başinda

Oturu ağlayasın

Yeşil yoncalar gibi

Açılmadan solasın (Duman 2011: 444).

Akşam oldi Eminem

İşuk yakalım işuk

Beddua ettim seni

Donatmayasın beşuk (Duman 2011: 444).

Akşam oldi Eminem

Yaksana işiğuni

Allah alsin elinden

Boyali beşuğuni (Duman 2011: 444).

Kocadun dura dura

Bobağun ocağında

Allah alsin canını

Kundağun kucaunda (Duman 2011: 444).

\section{6. Bilmeceler}

Ha gider, bu gider, bir garış yol gider. (Beşik) (Başgöz 1993a: 94).

Takur tukur takanı

İçinde var bakanı

İki tulum azı̆̆ 1

K... ındadır kazı̆̆ı (Beşik) (Başgöz 1993b: 633).

Taka taka taka o

Var içinde baka o

Demirden kazı̆̆ı var

Var g...ünde kazığı (Beşik) (Başgöz 1993b: 633). 
Taka taka takav

İçinde var pekav

İki tulum azığı

G...ünde var kazığı (Beşik, çocuk, meme, lazımlık) (Başgöz 1993b: 633).

T1kır tıkır tıklağıcan

İçinde var patlağıcan (Beşik) (Başgöz 1993b: 633).

Takur tukur takat1

İçindedir bakatı

İki tulum azı ğı

Arkasında kaşı̆̆ı (Beşik) (Başgöz 1993b: 633).

Takır takır takraba

İçinde var akraba (Beşik) (Başgöz 1993b: 633).

Taka taka takanica

İçinde var bakanica (Beşik) (Duman 2011: 436).

Takır takır takarı

İçindedir bakarı

Ağzındadır azığı

Altındadır kazığı (Beşik, çocuk, emzik ve sübek) (Ciravoğlu 2009:

79).

\section{7. İnanmalar}

"Boş beşik sallanırsa çocuğun karnı ağrır. " (Trabzon İl Yıllığı 2006: $82)$.

Boş beşiğin sallanması, babanın ölümüne sebep olur. (Durgun 2005:

$525)$.

\section{Sonuç}

Beşik, Türk kültürünün önemli bir parçasıdır. Geleneksel ahşap beşik, özellikle de göçebe kültürün bir gereği olarak Türk toplumunda yüzyıllarca kullanılmıştır. Bunun nedeni kolay taşınabilir ve pratik olmasıdır. Trabzon'un coğrafi yapısı düşünüldüğünde kolay taşınması geleneksel ahşap beşiği cazip hâle getirmektedir. Nitekim kadınlar, bebeklerini beşiğe yerleştirip beşiği de sırtına almak suretiyle tarlalara giderlerdi. Fakat günümüzde gerek yaşam tarzlarının değişmiş olması gerek modern beşiklerin 
çıkmasıyla geleneksel ahşap beşiklerin kullanımı yok denecek kadar azalmıştır. Bu nedenle üreticiler geleneksel ahşap beşikleri ancak sipariş üzerine yaptıklarını ifade etmektedir. Ayrıca üreticiler yörede geleneksel boyalı beşiklerin kalmadığını ve sipariş edilenlerin de müşterilerin isteklerine uygun olarak yapıldığını belirtmişlerdir.

Günümüzde bu sanatı devam ettiren ustalar turistik olarak yapılan süs eşyasına yönelmişlerdir. Küçük ebatlarda yapılan ahşap beşiklerin hediyelik ya da turistik amaçlı olarak kullanılmaya başlaması bu sanatı icra eden ustalar için umut kaynağı olmuştur. Fakat birçok ahşap ürün ustası geçinemediklerinden başka mesleklere yönelmişlerdir. Bu durum Trabzon el sanatçıllı̆ı açısından üzücü bir durumdur.

Her ne kadar maddi kültür olarak geleneksel ahşap beşik kullanımı azalmışsa da beşiğin sözlü kültür ürünlerinde canlı bir şekilde yaşadığı tespit edilmiştir. Beşiğin mânilerde, şiirlerde, atasözü ve deyimlerde, bilmecelerde, beddualarda, ağıtlarda yer alması halkın canlı hafızasında yaşadığı anlamına gelmektedir. Fakat kültür, her yönüyle bir bütündür. Bir sacayağının kırılması veya eksik olması diğer birimlerini de etkiler. Bu nedenle etkileşime ve değişime açık olan kültür geçmişten geleceğe bir bütün olarak taşınmalıdır. 


\section{KAYNAKÇA}

AKGÜNDÜZ, Ahmed (2002). "Bir Aile ve Hizmet Müessesesi Olarak Osmanlı'da Harem”, Türkler, Cilt 10: 572-633 Ankara: Yeni Türkiye Yayınları.

ARSEVEN, Celal Esad (1950). Sanat Ansiklopedisi, Cilt 3, İstanbul: Milli Eğitim Basımevi.

BAŞARAN, Fatma Nur ve Hanife YARMACI (2012). "Ağr1-Doğubayazit Yöresi Dokuma Beşik Örnekleri”, Süleyman Demirel Üniversitesi Güzel Sanatlar Fakültesi Hakemli Dergisi (9): 97-108. Yayınları.

BAŞGÖZ, İlhan (1993a). Türk Bilmeceleri 1, Ankara: Kültür Bakanlığ1 Yayınlar1.

BAŞGÖZ, İlhan (1993b). Türk Bilmeceleri 2, Ankara: Kültür Bakanlığ1

CİRAVOĞLU, Tevfik Vural (2009). Trabzon Folkloru, İstanbul: Türkmenler Mat.

ÇELİK, Ali (1994). “Trabzon Yöresi Ağıtları”, Milli Folklor, 3(23): 18-24. Yayınları.

ÇELİK, Ali (2005). Mânilerimiz ve Trabzon Mânileri, 1. Baskı, Ankara: Akçağ

DUMAN, Mustafa (2011). Trabzon Halk Kültürü, 1. Bask1, İstanbul: Heyamola Yayınları.

DURGUN, Hasan Hüsnü (Ed.) (2005) Geçmişten Geleceğe Çaykara Dernekpazarl, İstanbul: Seçil Ofset. Basımevi.

EREN, Hasan (1999). Türk Dilinin Etimolojik Sözlüğü, Ankara: Bizim Büro

ERGÖNENÇ AKBABA, Dilek ve Hasan BENLİ (2011). “Anadolu'da ve Kuzey Kafkasya'da Yaşayan Nogay Türklerinde Doğum Sonrası İnançlar”, Gazi Türkiyat Türkoloji Araştırmaları Dergisi, (9): 87-100.

EYNALLI, Ebru (2014). "Vakıfsever Bir Hanım Sultan: Mihrimah", Vakıf Restorasyon Yıllı̆̆

İSAYEV, Y. N. (2013). "Çuvaşçada ve Bazı Türk Şivelerinde "Ardıç" Kelimesinin Mitolojik Anlamı ve Etimolojisi”, Çev. Bülent Bayram, Türük Dil, Edebiyat ve Halkbilimi Araştırmaları Dergisi, (2): 432-435.

KARACA, Sabahattin (2000). Her Yönüyle Dünden Bugüne Ağasar-Şalpazarl, 1. Baskı, İstanbul: Göksu Grafik.

MUSTAFA, Ali (1982). “Beşik”, Kıyı Dergisi, (10): 3-8. 
MUSTAFA, Ali (2009) “Beşik”, Bir Şiirdir Trabzon Osmanlı'dan Günümüze Trabzon Şiir Antolojisi, ed. Mehmet Akif Bal, 1. Baskı içinde (125), Ankara: Cantekin Mat.

ÖKSÜZ, Selami (2005). “Güneşli'nin Son Beşikçileri”, Tekne Kültür-Sanat Dergisi, 3: 30-33.

SÜMERKAN, M. Reşat (1982). “Doğu Karadeniz Köylerinde Renk Beğenisi”, Klyı Dergisi, 15: 10-13.

Trabzon Il Yıllı̆̆g (2006). Trabzon: İl Kültür ve Turizm Müdürlüğü Yayınları.

Türk Ansiklopedisi (1974). Cilt 21, Ankara: Milli Eğitim Basımevi.

YILDIZ, M. Cengiz (2013). "Harput’taki Ziyaret Yerleri Etrafinda Oluşan Ritüellere Din Sosyolojisi Açısından Bakış", Fırat Üniversitesi Harput Uygulama ve Araştırma Merkezi Geçmişten Geleceğe Harput Sempozyumu, ss. 879-892, Elazı̆̆.

\section{Kaynak Kişiler} 2012).

K 1: İsmail Avc1, Köprübaşı 1961, Lise Mezunu, Esnaf. (Görüşme: 06.06. 2012).

K 2: Hasan Çin, Sürmene 1972, Ortaokul Mezunu, Esnaf. (Görüşme: 06.06. 